\title{
High molecular weight glutenin subunit variation in the Sitopsis section of Aegilops. Implications for the origin of the $B$ genome of wheat
}

\author{
Begoña Fernández-Calvín and \\ Juan Orellana
}

\author{
Unidad de Genética, E.T.S.I. Agrónomos, \\ Universidad Politécnica de Madrid, 28040 Madrid, \\ Spain.
}

Variation in high molecular weight (HMW) glutenin subunit composition among Aegilops species of the Sitopsis section, namely Ae. bicornis, Ae. longissima, Ae. sharonensis, Ae. searsii and Ae. speltoides was investigated using one-dimensional, as well as two step one-dimensional (2S-1D), sodium dodecyl sulphate polyacrylamide gel electrophoresis (SDS-PAGE). The presence of three glutenin bands in several accessions of Ae longissima and Ae. sharonensis seems to be evidence for the existence of at least three active genes, called $x, y$ and $z$, controlling the synthesis of the high molecular weight glutenins in the genome $\mathrm{S}$ of Aegilops. From comparisions between the glutenin patterns found in the species analysed and those bands observed for the $B$ genome of hexaploid wheat, it can be concluded that Ae. bicornis, Ae. longissima and Ae. sharonensis are unlikely donors of the B genome, mainly because of the presence of specific glutenin markers that were absent in wheat. Ae. searsii and Ae. speltoides showed glutenin subunits that moved within the range of those of $\mathrm{B}$, but Ae. speltoides is the only species that could explain the variablity for HMW subunits previously described for the $B$ genome of wheat, and therefore it cannot be excluded as a possible donor of this genome.

\section{INTRODUCTION}

It has been generally accepted that the A genome of both tetraploid and hexaploid wheats is derived from Tritıcum monococcum and the D genome of hexaploids from Aegilops squarrosa. However, the source of the B genome remains unresolved. Thus, karyotypic analysis, chromosome pairing and banding patterns, comparative studies of monomorphic protein markers, restriction patterns of chloroplast and mitochondrial DNA, and morphological characteristics, have been used as criteria for determining the donor species of the B genome (see Kerby and Kuspira, 1987 for a review).

The high molecular weight (HMW) glutenins of wheat have been extensively analysed over recent years, and much progress has been made in characterizing glutenin subunits both genetically and biochemically, mainly due to their relationship with breadmaking quality in hexaploid wheat (see Law and Payne, 1983; Payne, 1987). In contrast, HMW glutenins have not been well characterized in species related to wheat, in spite of their much wider range of genetic variability for grain proteins.
This variation can be used not only for genetic improvement but also in evolutionary studies (Feldman et al., 1986).

The aim of this work is to analyse the variability for the HMW glutenin subunits in several accessions of Aegilops species included in the Sitopsis section, probable donors of the B genome.

\section{MATERIAL AND METHODS}

The seeds analysed in the survey of variation for high molecular weight (HMW) subunits included eleven accessions of Ae. bicornis (four from Egypt, one from Israel and six from unknown origin), twenty six accessions of Ae. longissima (twenty from Israel, two from Jordan and four from unknown origin), four accessions of Ae. searsii (one from Syria and three from unknown origin), seven accessions of Ae. sharonensis (four from Israel and three from unknown origin), forty one accessions of $A e$. speltoides (one from Israel, seven from Iraq, fifteen from Israel, twelve from Turkey and six from unknown origin) and fourteen hexaploid wheat cultivars usually employed as 
standards for HMW glutenins (Payne and Lawrence, 1983).

At least ten different seeds from each accession were studied by SDS-PAGE.

Unreduced proteins were extracted from endosperm halves of single kernels using sample buffer without 2-mercapto-ethanol (2-ME) and separated in 10-12 per cent polyacrylamide gel electrophoresis as described by Payne et al. (1980). The unreduced extracts were later reduced with one drop of 2-ME and subjected to further SDS-PAGE 10-12 per cent gel in order to observe the high molecular weight proteins.

The same unreduced extracts were also analysed using the two step-one dimensional (2S-1D) method described by Singh and Shepherd (1988), with some modifications. In the first step $400 \mu$ l of each extract was run for about 1 hour in separate gel tubes ( $5 \mathrm{~mm}$ thick), instead of several slots in the same slab, in normal SDS-PAGE, and the top $1 \mathrm{~cm}$ portion was cut and transferred into sample buffer with 2-ME for reduction. Subsequently these reduced protein samples were run as described above for reduced extracts.

The bread wheat varieties "Danchi" and "Hope" were used as standards in all electrophoresis because their high molecular weight subunits covered the migration range of HMW glutenins rather well. The number assignations of wheat bands was carried out according to Payne and Lawrence (1983).
In all cases the molecular weight markers used were the Sigma MW-SDS-200 kit that includes myosin $(205,000), \beta$-galactosidase $(116,000)$, phosphorylase B $(97,400)$, bovine albumin $(66,000)$, egg albumin $(45,000)$ and carbonic anhydrase $(29,000)$.

\section{RESULTS}

The HMW glutenins are important components of the total seed storage proteins. This fraction forms large disulphide linked agregates that can be broken into their component subunits (80$140 \mathrm{kd}$ ) by treatment with an agent that breaks disulphide bonds, such as 2-ME, and an agent which disrupts, either directly or indirectly, hydrophobic interactions and hydrogen bounds, such as the anionic detergent (see Bietz and Wall, 1972; Kasarda et al., 1976; Ewart, 1988), Thus, these subunits are not detectable by electrophoresis when the proteins samples were fractioned by SDSPAGE without prior reduction with 2-ME since the aggregates could not penetrate the pores of the polyacrylamide gel. Converseley, proteins that did not form aggregates were not present in the second step and were not retained on the top of the gel. These properties are typical of glutenin proteins of wheat (see Waines and Payne, 1987) and it would be assumed that the HMW proteins studied in the following Aegilops species are equivalent to those glutenin subunits of wheat.
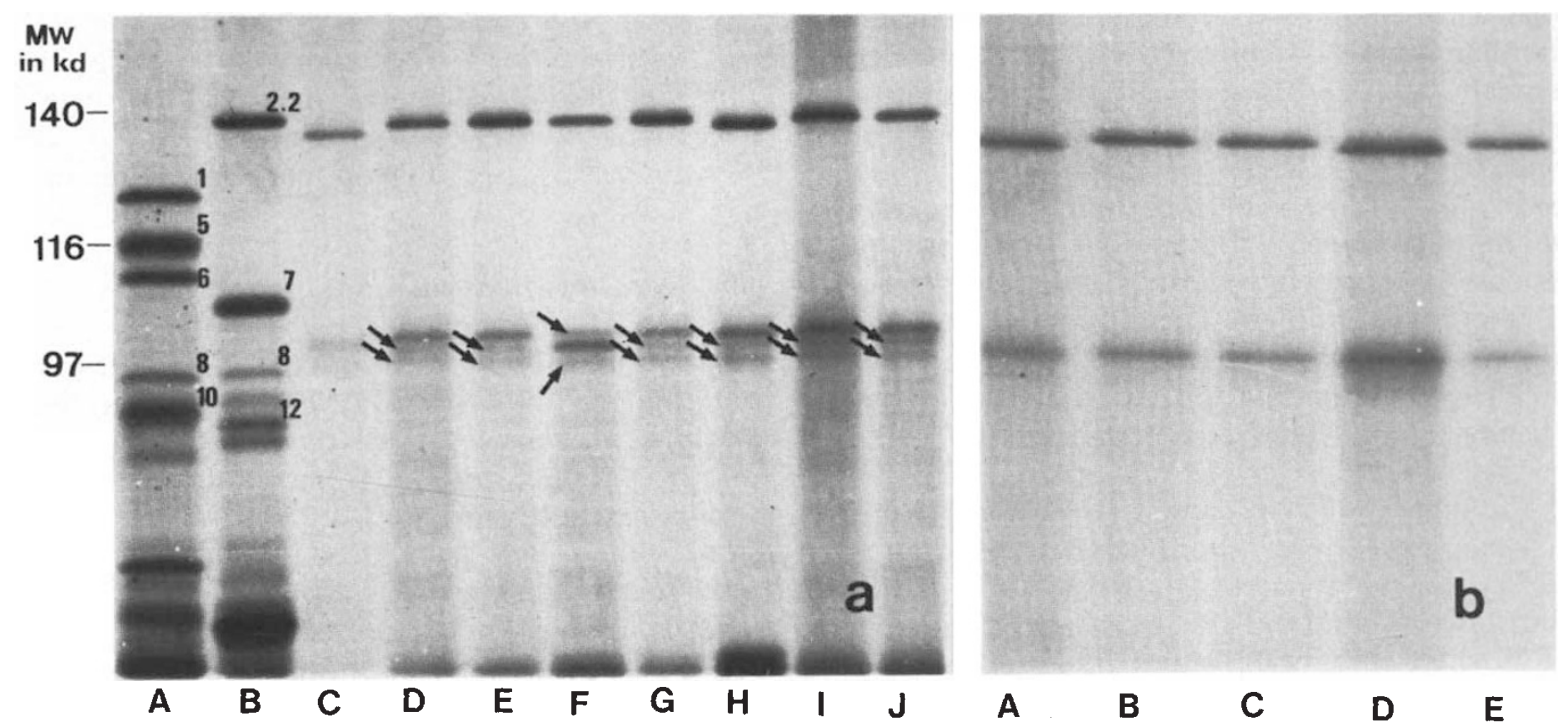

Figure 1 SDS-PAGE migration patterns of HMW glutenins extracted from the samples of Ae. bicornis. (a) Reduced total seed proteins. A. $c v$. Hope, B. $c v$. Danchi, C-J. accessions 2, 3, 4, 7, 6, 5, 8, and 9 of Ae. bicornis. (b) 2S-1D SDS-PAGE. A-E. accessions 2, 3, 4, 5, and 6 of Ae. bicornis. Arrows indicate minor bands that disappeared when the 2S-1D method is employed. 

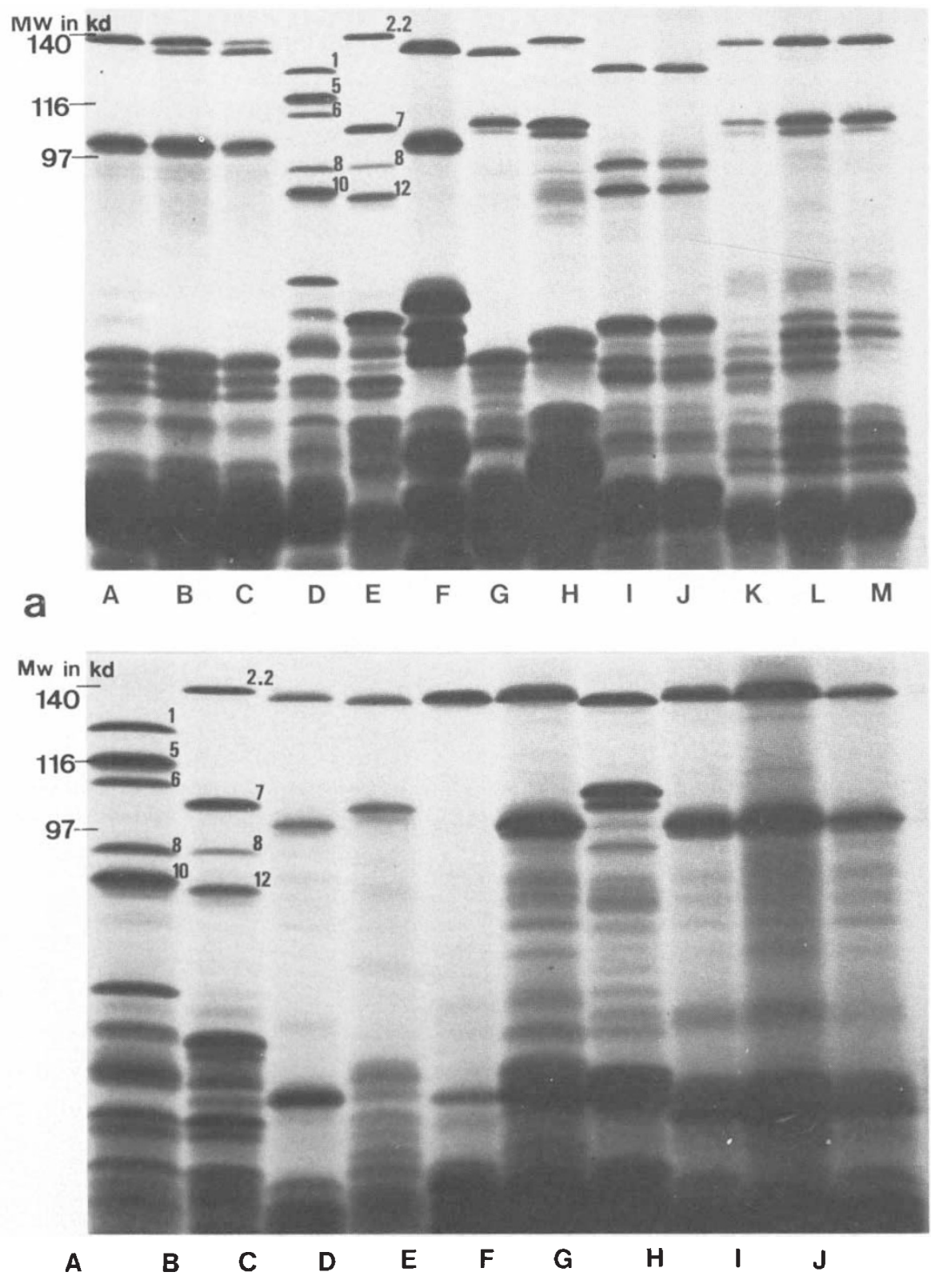

Figure 2 SDS-PAGE migration patterns of HMW glutenins from several accessions of Ae. longissima and Ae. sharonensis. (a) Ae. longissima A-C. extracts from accession 2, D. cv. Hope, E. $c v$. Danchi, F-J. accessions 8, 10, 24, 25 and 26, K-M. extracts from different seeds of accession 11. (b) Ae. sharonensis A. cv. Hope, B. cv. Danchi, C-G. accessions 1, 2, 3, 4, 5., H-J. several extracts of accession 6 .

The eleven accessions analysed in Ae. bicornis showed a very similar pattern formed by two different electrophoretic moving zones. The slowmoving zone was represented by only one band whose migration was equal to or slightly faster than 2.2 of $c v$. Danchi. The fast-moving zone was composed of one major band and two close minor bands located between bands 7 and 8 of $c v$. Danchi (fig. 1(a)). However, only the major band was retained when the $2 S-1 D$ method was employed (fig. 1(b)).

The patterns observed in Ae. longissima were more variable. All accessions showed two migrating zones, the slower located between bands $2 \cdot 2$ 
and 1 of $c v$. Danchi and Hope, respectively. In all accessions this zone was represented by only one band except accession 2 that showed two patterns, one with only one band and the other with two bands (see fig. 2(a), slots A, B and C). The fastermoving zone was composed of two subunits situ- ated between bands 7 and 8 of $c v$. Danchi, except accessions 25 and 26 that showed two more widely separated bands, one with similar mobility to band 8 and the other at the mobility of band 12 of $c v$. Danchi. Accessions 2 and 8 showed only one wide band for the faster moving zone, Multiple minor
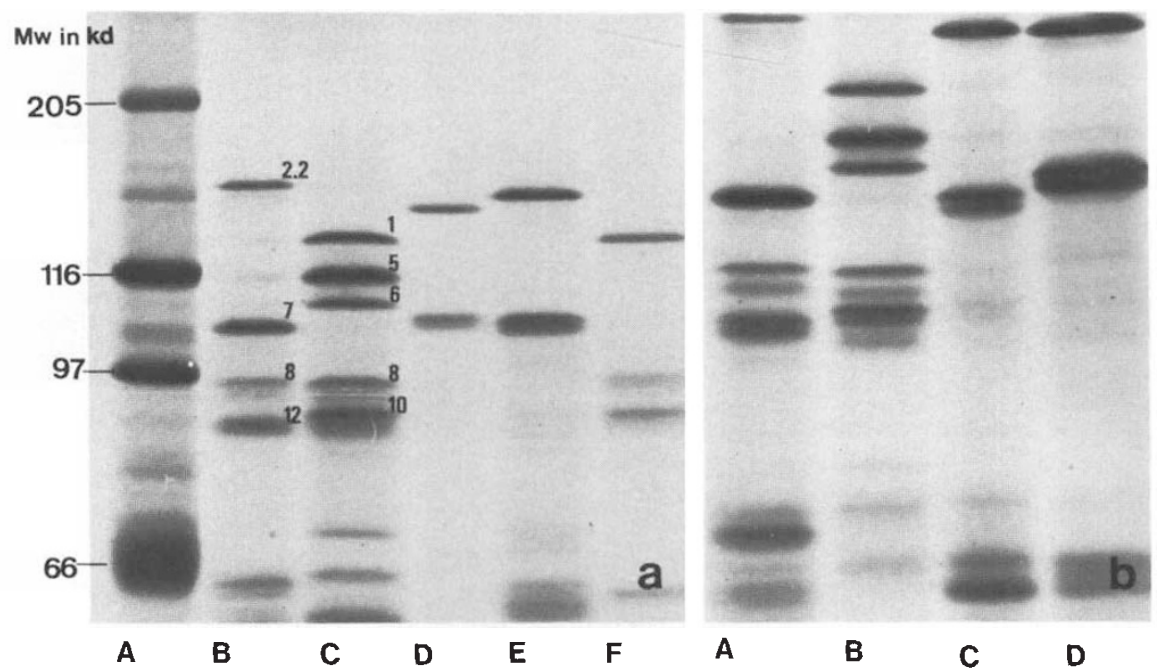

Figure 3 2S-1D SDS-PAGE of Ae. longissima and Ae. sharonensis. (a) Ae. longissima A. molecular weight markers, B. cv Danchi, C. $c v$. Hope, D. accession 10, E. accession 11, F. accession 25. (b) Ae. sharonensis A. cv Danchi, B. cv. Hope, C. accession 4, D. accession 5 .
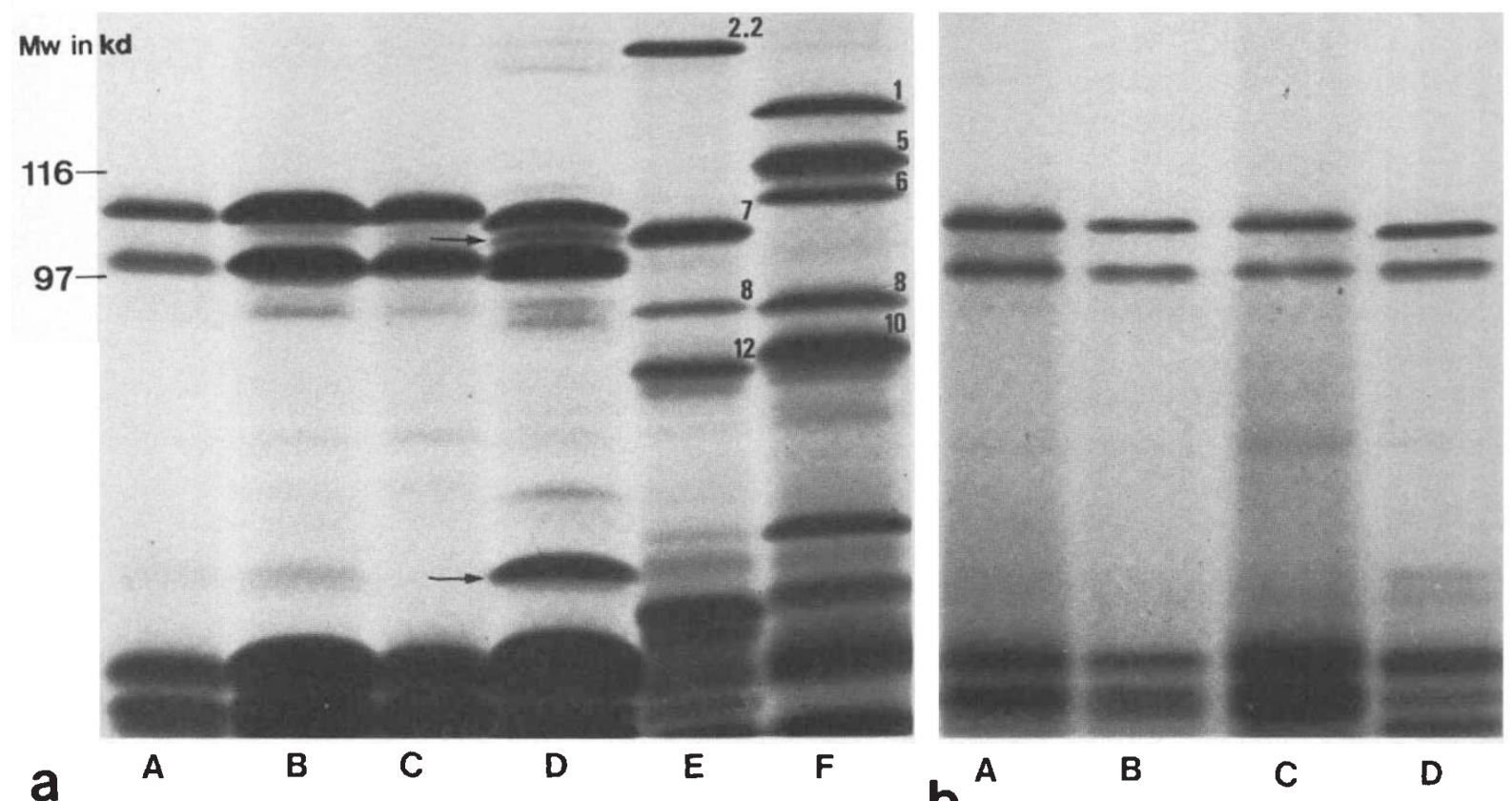

a A

B

C

E

$\mathbf{F}$

b

Figure 4 SDS-PAGE migration patterns of HMW glutenins extracted from samples of Ae. searsii, (a) Reduced total seed proteins. A-D. accesions 2, 3, 4 and 5, E. $c v$. Danchi, F. cv. Hope. (b) 2S-1D SDS-PAGE. A-D. accessions 2, 3, 4, and 5. Arrows indicate bands that disappeared when the $2 \mathrm{~S}-1 \mathrm{D}$ method was employed. 
bands have also been observed in several accessions, but these bands have not been considered in this study (fig. 2(a)).

In Ae. sharonensis all accessions showed two zones of migration, one of them located very closed to band 2.2 of $c v$. Danchi as in Ae. bicornis and the other between bands 7 and 8 , except accession 3 that did not show any band for the faster moving zone (fig. 2(b), slot E). As in Ae. longissima, accessions 4 and 5 showed a double band for the faster zone (fig. 2(b)).

In both species these double bands observed for the faster moving zone also appeared when the 2S-1D method was employed (fig. 3), indicating that they form disulphide linked aggregates.

In $A e$. searsii a very constant pattern formed by two subunits was found, one located between bands 6 and 7 of wheat and other between bands

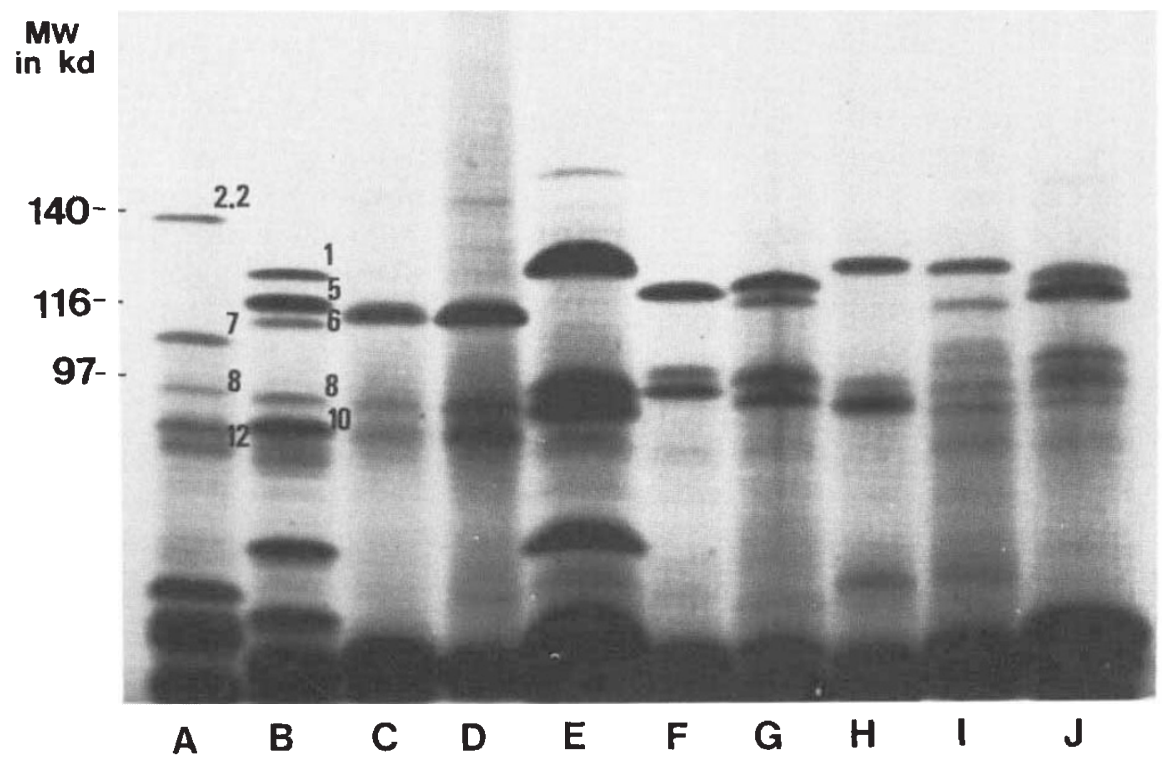

Figure 5 SDS-PAGE patterns of total seed reduced proteins from several accesions of Ae. speltoides. A. $c v$. Danchi, B. $c v$. Hope, C-J. accessions $5,2,4,3,1,20,16$, and 17 .

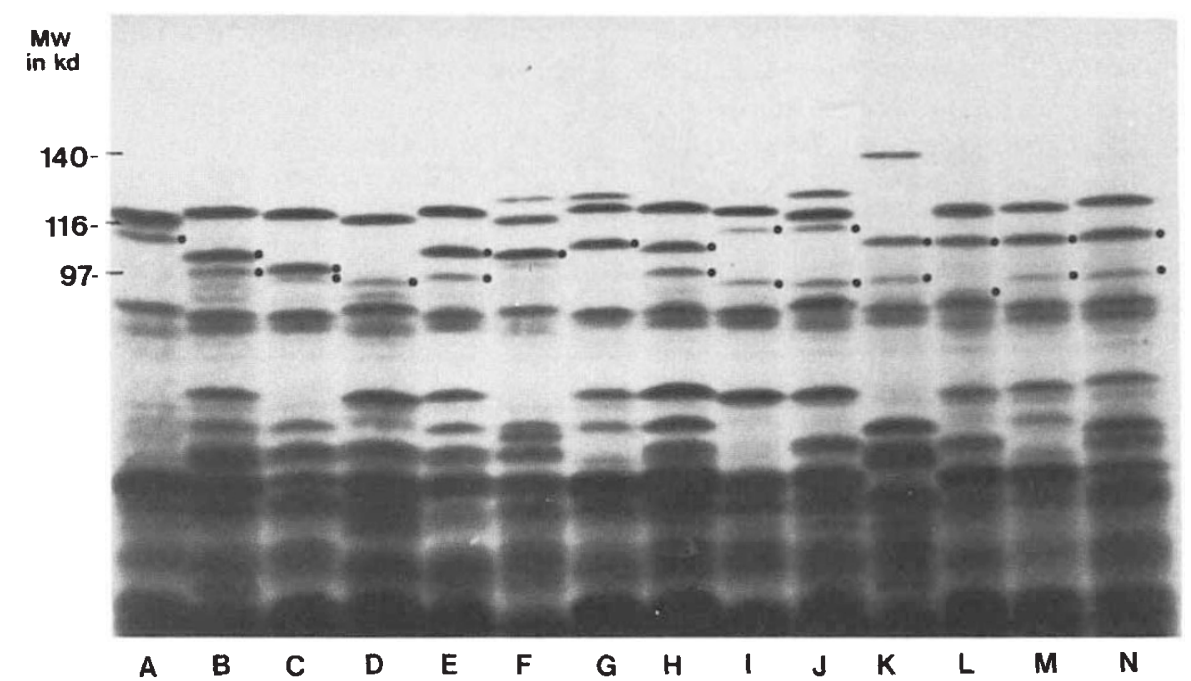

Figure 6 SDS-PAGE patterns of total seed reduced proteins from several wheat cultivars normally used as standards. A. Zorba, B. Sappo, C. Sandown, D. Serbian, E. Lancota, F. Federation, G. Flinor, H. Frondoso, I. Hobbit, J. Hope, K. Danchi, L. Bezostaya-I, M. Champlein, N. Chinese Spring. Fill points indicate bands of the B genome. 
7 and 8 of $c v$. Danchi (fig. 4(a)). It is worth mentioning that in accession 5 appeared an extra thin band between the two major subunits, (fig. 4(a), slot D) but that band could not be considered as a glutenin protein because it disappeared when the 2S-1D method was employed (fig. 4(b)).

As expected Ae. speltoides showed the most variable patterns of the species analysed here. This variability could be a reflection of the allogamous reproductive system of this taxon. In all accessions analysed, a great number of patterns formed by several subunits were found, and no one specific mobility zone could be determined, but even so, all bands were located between or near bands 1 and 10 of $T$. aestivum (see fig. 5 and 6).

In Ae. longissima and Ae. speltoides, where the number of bands observed were sufficiently high, a more detailed analysis was made in order to determine the percentage of subunits with the same electrophoretic mobility that those described for the B genome of wheat by Payne and Lawrence (1983). All accessions of Ae. longissima and two seeds of each accessions of Ae. speltoides were compared with glutenin subunits of standards. In Ae. longissima 27 of the total 58 bands (46.55\%) and 129 of the total 234 bands ( $55 \cdot 13$ per cent) in Ae. speltoides showed the same mobility as subunits of the B genome.

\section{DISCUSSION}

Numerous experiments have been undertaken to establish the phylogeny of the polyploid wheats. Although it is accepted that $\mathrm{A}$ and $\mathrm{D}$ genomes are derived from those of $T$. monococcum and $A e$. squarrosa respectively, evidence about the origin of the B genome of $T$. turgidum and $T$. aestivum is still contradictory (see Kerby and Kuspira, 1988).

Comparative analysis of HMW glutenin subunits could provide additional information for identification of the putative parental species of the $\mathrm{B}$ genome. These proteins are the products of the activity of what have been termed complex loci or gene clusters located on homoeologous group 1 in Triticum and related species (Bietz et al., 1975; Payne et al., 1980, 1982; Lawrence and Shepherd, 1981; Galili and Feldman, 1983; Levy et al., 1985).

Generally, in all species studied, these clusters contain two genes, namely $x$ controlling the subunit that shows the slower electrophoretic mobility and $y$ controlling the subumit with faster electrophoretic mobility (Forde et al., 1985; Harberd et al., 1986; Waines and Payne, 1987). In some cases, two or more bands were observed for the faster moving zone. These subunits appeared as a closely migrating doublet, that always co-migrated and were formed by a wide band (the slowest) and a faint band (the fastest) in most of the cases (see slots G, H, K, L. M in fig. 2(a) and F, G in fig. 2(b)).

It has been suggested by Holt et al. (1981) that these double bands are either products of the same gene or, alternatively, products of two closely linked and duplicated genes. This assumption is supported by the similarities found for their mobility in two-dimensional electrophoresis (Holt et al., 1981), amino acid composition and patterns after protease digestion (Galili and Feldman, 1985). The data of tetraploid wheats reported by Levy et al. (1988) strongly indicate that such bands are controlled by a single gene, since in all electrophoretic patterns the two subunits were either present or absent and they were always of very similar mobility. If they were encoded by two different genes their allelic variation may not always result in such an electrophoretic pattern. As pointed out by Levy et al. (1988) there are several molecular mechanisms to produce two polypeptides from a single gene; one of them could imply proteolytic activity either during endosperm development or protein extraction (Holt et al., 1981; Harberd et al., 1986; Waines and Payne, 1987). This last mechanism could be responsible for faster moving double bands observed in several tetraploid species of Aegilops (Vazquez et al., unpublished). In that case the fastest subunit of the doublet disappeared in all accessions in which the 2S-1D method was employed. This was explained by suggesting that the modified polypeptides (proceeding from proteolytic activity) did not form disulphide-linked aggregates and therefore were eliminated in the first step. This seems to be the case for the minor bands found in Ae. bicornis (fig. 1(a), 1(b)) but not for those observed in Ae. longissima and Ae. sharonensis, where neither band of the doublets disappeared using the two steps (fig. 2 and 3). In addition, accessions 25 and 26 of Ae. longissima showed two well separated bands that could not be classified as doublets (see slots I, J in fig. 2(a) and slot $\mathrm{F}$ in fig. 3(a)), and similar results have been also observed in Ae. uniaristata (Vazquez et al., unpublished).

The appearance of three bands could be also explained by the existence of heterozygous plants for glutenin loci. Consequently, plants of different accessions showing three bands were self-pollinated and the progeny of each plant was analysed by SDS-PAGE. In all cases the electrophoretic pattern was the same as that observed in the paren- 
tals, except in accession 2 in which segregation for the slow moving zone was found. Therefore there is good evidence for assuming that in Ae. longissima and, probably, in Ae. sharonensis there must be at least a third gene, called $z$, for HMW glutenins, although further genetic analysis should be made in order to confirm this hypothesis. The presence of more than three bands in Ae. speltoides could be explained by the existence of heterozygous plants, since Ae. speltoides is an allogamous species.

The variation in the amount and type of grain proteins is the main factor responsible for determining the differences in breadmaking quality and nutritional properties of flours. The unique cohesive-elastic properties of doughs made from flour of hexaploid wheat result primarily from the properties of the gluten proteins (Krull and Wall, 1969; Kasarda et al., 1971), and there is strong evidence that the presence of specific HMW glutenin subunits is correlated positively with improved breadmaking quality (see Payne, 1987). These findings indicate the importance of determining the genetic variation of genes controlling glutenins in wheat and its relatives. The new variation found in the Aegilops species studied in this work could be a valuable source for improving breadmaking quality in wheat, by transferring new subunits and/or increasing the number of subunits by using those species, such as Ae. longissima and $A e$. sharonensis, in which the three supposed genes are actively expressed.

The comparisons between the electrophoretic patterns found in Aegilops species of the Sitopsis section seem to indicate that Ae. bicornis can be excluded as the donor of the B genome of wheat. This species showed a very constant pattern bearing one band with a very similar mobility to that of band $2 \cdot 2$ of $c v$. Danchi in all accessions (fig. 1); in addition the persistency of that pattern is not in accordance with the variability found for glutenins in the B genome (fig. 6). Similar conclusions have been reached by Kerby and Kuspira (1988) from karyotypic studies, and by Natarajan and Sarma (1974) from comparisions of chromosome banding patterns.

Ae. longissima and Ae. sharonensis showed more variable patterns, but again both species consistently show a band with similar mobility to that of band $2 \cdot 2$ of Danchi, absent from the B genome. In addition, it seems clear that Ae. longissima and Ae. sharonensis have three genes for the high molecular weight glutenins, whereas for the B genome only two copies of such genes have been described (Payne et al., 1982). This result, although indicative, could not be a reason for excluding these species as donors of the B genome because plants or accessions with null alleles might be implicated in the evolution of wheat, as has been demonstrated for the A genome of $T$. monococcum (Waines and Payne, 1987).

Ae. sharonensis does not show the same karyotypic characteristics of the B genome (Kerby and Kuspira, 1988); however, Natarajan and Sarma (1974) indicated that the distribution of C-hetrochromatin in the chromosomes of Ae. sharonensis is very similar to that observed for chromosomes of the B genome, whereas Ae. longissima does not show such a C-banding pattern. By contrast, Ogihara and Tsunewaki (1982) and Tsunewaki and Ogihara (1983) found that the restriction patterns of chloroplast DNA from T. turgidum was identical to that of Ae. longissima. Konarev et al., (1976, 1979), and Konarev (1983) showed that some albumins and gliadins in Ae. longissima and Ae. searsii were identical both to one another and to those controlled by the B genome in polyploid wheats.

The HMW glutenins observed in Ae. searsii are in the range of mobility found for the subunits of the B genome (between bands 5 and 10). However all accessions analysed showed similar patterns with a very constant location and little variation (see fig. 4). By contrast the B genome is the most variable for HMW glutenins in wheat. Although the number of accessions analysed in this work is very limited, the protein patterns observed in $A e$. searsii do not clearly resemble the glutenin subunits of the B genome of wheat. This conclusion is in agreement with that suggested by Chen and Gill (1983) from the C-banding patterns of Ae. searsii chromosomes. However, Feldman and Kislev (1977) have suggested that Ae. searsii is the probable donor of the $B$ genome since it is the only species in the Sitopsis section that has a sympatric distribution with both $T$. turgidum and $T$. monococcum, and its satellite chromosomes show the same morphology as that of chromosomes 1B and $6 \mathrm{~B}$ of T. aestivum (Feldman, 1978). The karyotypic analysis carried out by Kerby and Kuspira (1988) seems to indicate the same conclusions.

Ae. speltoides was the most variable species analysed in this work and should not be excluded as the donor of the B genome. There were a great number of plants that showed glutenins with an electrophoretic mobility within the range of the HMW subunits for the B genome, and its variability could explain that observed in wheat. In fact, many of those bands of Ae. speltoides (55.13 per cent) have the same electrophoretic mobility as the 
fourteen subunits of the B genome analysed in the standards wheats. Probably, the mobility of another subunit encoded by chromosome 1B (see Vallega and Waines, 1987; McIntosh, 1988) might coincide with the mobility of any other of Ae. speltoides due to the variation found in this species. Many workers have arrived at this conclusion studying morphological characteristics (Sarkar and Stebbins, 1956), satellite chromosomes (Riley et al. 1958) cytoplasmic proteins (Barhman et al. 1988) chromosome banding (Chen and Gill, 1983), and amount of nuclear DNA (Rees, 1963; Rees and Walters, 1965) whereas many others have excluded it using the same type of analysis (Waines and Kimber, 1973; Natarajan and Sarma, 1974; Gill and Kimber, 1974; Hadlaczky and Belea, 1975; Iodansky et al., 1978; Kerby and Kuspira, 1988).

Probably the contradictory results obtained from different studies could be explained because each type of experiment can only provide limited information. Thus chromosome morphology and banding patterns cannot be taken as an accurate methodology because in many cases chromosome morphology may have changed by chromosome rearrangments, and usually there is an extensive C-banding polymorphism, not only between different species, but also within a given species, which makes comparision difficult. In the same way, protein and isozyme studies could be very useful, but only a few loci are usually available for analysis. From the results obtained from different sources it seems clear that the B genome donor might be a species with as high a level of polymorphism as Ae. speltoides, and the analysis of a great number of accessions would be required to identify it unequivocally.

Acknowledgements We thank Dr Ohta, Plant Germplasm Institute, Kyoto, and Dr J. Kuspira, University of Alberta, Edmonton, Canada, for supplying some of the Aegilops stocks analysed in this study. We would also like to thank Dr J.M. Carrillo for his helpful comments and suggestions concerning the manuscript and $\mathrm{Mr} \mathrm{J}$. Rodriguez-Contreras for his experimental assistance. We are greatly indebted to Dr C. García de la Vega for his encouragement and stimulating conversations. This work has been supported by a grant No. AGR88-0051 from the Comision Interministerial de Ciencia y Tecnología (CICYT) of Spain.

\section{REFERENCES}

BAHRMAN, N., ZIVY, M. AND THIELLEMENT, H. 1988. Genetic relationships in the Sitopsis section of Triticum and the origin of the B genome of polyploid wheats. Heredity, 61 , 473-480.
BIETZ, J. A., SHEPHERD, K. W. AND WALL, J. S. 1975. Single kernel analysis of glutenin: Use in wheat genetics and breeding. Cereal Chem., 52, 513-532.

BIETZ, J. A. AND WALL, J. S. 1972. Wheat glutenin subunits: molecular weights determined by sodium dodecyl sulphatepolyacrylamide gel electrophoresis. Cereal Chem., 49, 416430.

CHEN, P. D. AND GILL, B. S. 1983. The origin of chromosome 4A, and genomes B and G of tetraploid wheats. Proc. 6th. Int. Wheat Genet. Symp., Kyoto, Japan, pp. 39-48.

EWART, J. A. D. 1988. Studies on disulfide bonds in glutenin. Cereal Chem., 65, 95-100.

FELDMAN, M. 1978. New evidence on the origin of the B genome of wheat. Proc. Int. Wheat Genet. Symp. 5th., 1, $120-132$

FELDMAN, M., GALILI, E. AND LEVY, A. A. 1986. Genetic and evolutionary aspects of allopolyploidy in wheat. Proc. Symp. Origin Domestication of Cultivated plants. In Brigozzi, C. (ed.) Academia Nazionale dei Lincei Rome, Elsevier, Amsterdam, Oxford, New York, Tokyo, pp. 83100

FELdMAN, M. AND KISLEV, M. 1977. Aegilops searsii, a new species of the section Sitopsis (Platystachys). Isv. J. Bot., 26, 190-201.

FORDE, J., MALPICA, J. M., HALFORD, N. G., SHEWRY, P. R., ANDERSON, O. D., GREENE, F. C. AND MIFLIN, B. J. 1985 The nucleotide sequence of a HMW glutenin subunit gene located on chromosome 1A of wheat (Triticum aestivum). Nucleic. Acids Res., 13, 6817-6832.

GALILI, G. AND FELDMAN, M. 1983. Genetic control of endosperm proteins in wheat. 1. The use of high resolution one-dimensional gel electrophoresis for the allocation of genes coding for endosperm protein subunits in the common wheat cultivar Chinese Spring. Theor. appl. Genet, 64, 97-101.

GALILI, G. AND FELDMAN, M. 1985. Structural homology of endosperm high molecular weight glutenin subunits of common wheat (Triticum aestivum L.). Theor. appl. Genet., 70, 634-642.

GILL. B. S. AND KIMBER, G. 1974. Giemsa C-banding and the evolution of wheat. Proc. Natl Acad. Sci. USA, 71, 40864090.

HADLACZKY, G. AND BELEA, A. 1975. C-banding in wheat evolutionary cytogenetics. Pl. Sci. Lett. 4, 85-88.

HARBERD, N. P., BARTELS, R. D. AND THOMSON, R. D. 1986. DNA restriction fragment variation in the gene family encoding high molecular weight (HMW) glutenin subunits of wheat. Biochem. Genet., 24, 579-596.

HOLT, L. M., ASTIN, R. AND PAYNE, P. 1. 1981. Structural and genetical studies on the high-molecular-weight subunits of wheat glutenin. 2. Relative isoelectric points determined by two-dimensional fractionation in polyacrylamide gels. Theor appl. Genet, 60, 237-243.

IODANSKY, A. B., ZURABISHVILI, T. B. AND BDAEV, N. S. 1978. Linear differentiation of cereal chromosomes. I. Common wheat and its supposed ancestors. Theor. appl. Genet., 51, 145-152.

KASARDA, D. D., BERNARDIN, J. E. AND NIMMO, C. C. 1976. Wheat proteins. In Pomeranz, V. (ed.) Advances in cereal science and technology. Am. Assoc. Cereal Chem., St. Paul, Minnesota, pp. 158-236.

KASARDA, D. D., NIMHO, C. C. AND KOHLER, G. O. 1971 Proteins and the amino acid composition of wheat fractions. In Pomeranz, V. (ed.) Wheat Chemistry and Technology, 2nd. edn Amer. Assoc. Cereal Chemists Inc., St. Paul, Minnesota, pp. 227-299. 
KERBY, K. AND KUSPIRA, J. 1987. The phylogeny of the polyploid wheats Triticum aestivum (bread wheat) and Triticum turgidum (macaroni wheat) Genome, 29, 722-737.

KERBY, K. AND KUSPIRA, J. 1988. Cytological evidence bearing on the origin of the B genome in polyploid wheats. Genome, $30,36-43$.

KONAREV, V. G. 1983. The nature and origin of wheat genomes on the data of grain protein inmunochemistry and electrophoresis. Proc. Int. Wheat Genet. Symp. 6th, pp. 65-75.

KONAREV, V. G., GAVRILYUK, I. P., GUBAREVA, N. K. AND PENEVA, T. I. 1979. Seed protein in genome analysis, cultivar identification and documentation of cereal genetic resources: a review. Cereal Chem., 56, 272-278.

KONAREV, V. G., GAVRILYUK, I. P. AND PENEVA, T. I. 1976. About nature and origin of wheat genome on the data of biochemistry and inmunochemistry of grain proteins. $S k h$. Biol., 11, 656-665.

KRULL, L. H. AND WALL, J. S. 1969. Relationship of amino acid composition and wheat protein properties. Baker's Diq., $43,30-39$.

LAW, C. N. AND PAYNE, P. I. 1983. Genetical aspects of breeding for improved grain protein content and type in wheat. $J$. Cereal Sci., 1, 79-93.

LAWRENCE, G. J. AND SHEPHERD, K. W. 1981. Chromosomal location of genes controlling seed proteins in species related to wheat. Theor. appl. Genet., 59, 25-31.

LEVY, A. A., GALILI, G. AND FELDMAN, M. 1985. The effect of additions of Aegilops longissima chromosomes on grain protein in common wheat. Theor. appl. Genet., 69, 429-435.

LEVY, A. A., GALILI, G. AND FELDMAN, M. 1988. Polymorphism and genetic control of high molecular weight glutenin subunits in wild tetraploid wheat Triticum turgidum var. dicoccoides. Heredity, 61, 63-72.

McINTOSH, R. A. 1988. Catalogue of gene symbols of wheat. 7th. Inter. Wheat Genet. Symp. Cambridge, England, pp. 1255-1323.

NATARAJAN, A. T. AND SARMA, N. P. 1974. Chromosome banding patterns and the origin of the $B$ genome in wheat. Genet. Res., 24, 103-108.

OGIHARA, Y. AND TSUNEWAKI, K. 1982. Molecular basis of the genetic diversity of the cytoplasm in Triticum and Aegilops. I. Diversity of the chloroplast genome and its lineage revealed by the restriction pattern of ct-DNAs. Jpn. J. Genet., 57, 371-396.

PAYNE, P. I. 1987. Genetics of wheat storage proteins and the effect of allelic variation on breadmaking quality. A. Rev. Pl. Physiol., 38, 141-153.
PAYNE, P. I., HOLT, L. M., WORDLAND, A. J. AND LAW, C. N. 1982. Structural and genetical studies on the highmolecular-weight subunits of wheat glutenin. Part 3 . Telocentric mapping of the subunit genes on the long arms of the homoeologous group 1 chromosomes. Theor. appl. Genet., 63, 129-138.

PAYNE, P. I., LAW, C. N. AND MUDD, E. E. 1980. Control by homoeologous group 1 chromosomes of the high molecular weight subunits of glutenin, a major protein of wheat endosperm. Theor. appl. Genet., 58, 113-120.

PAYNE, P. I. AND LAWRENCE, G. J. 1983. Catalogue of alleles for the complex gene loci, Glu-Al, Glu-Bl and Glu-Dl which code for high-molecular-weight subunits of glutenin in hexaploid wheat. Cereal Res. Commun., 11, 29-35.

REES, H. 1963. Deoxyribonucleic acid and the ancestry of wheat. Nature, 198, 108-109.

REES, H. AND WALTERS, M. R. 1965. Nuclear DNA and the evolution of wheat. Heredity, 20, 73-82.

RILEY, R., UNRAU, J. AND CHAPMAN, V. 1958. Evidence on the origin of the B genome of wheat. J. Hered., 49, 91-98.

SARKAR, P. AND STEBBINS, G. L. 1956. Morphological evidence concerning the origin of the B genome in wheat. Am. J. Bot., 43, 297-304.

SINGH, N. K. AND SHEPHERD, K. W. 1988. Linkage mapping of genes controlling endosperm storage proteins in wheat. 1 . Genes on the short arms of group 1 chromosomes. Theor. appl. Genet., 75, 628-641.

TSUNEWAKI, K. AND OGIHARA, Y. 1983. The molecular basis of genetic diversity among cytoplasm of Triticum and Aegilops species. II. On the origin of polyploid wheat cytoplasms as suggested by chloroplast DNA restriction fragment patterns. Genetics, 104, 155-171.

VALLEGA, V. AND WAINES, J. G. 1987. High molecular weight glutenin subunit variation in Triticum turgidum var. dicoccum. Theor. appl. Genet., 74, 706-710.

WAINES, J. G. AND KIMBER, G. 1973. Satellite number and size in Triticum monococcum L. and the evolution of the polyploid wheats. Can. J. Cytol., 15 117-122.

WAINES, J. G. AND PAYNE, P. I. 1987. Electrophoretic analysis of the high-molecular-weight glutenin subunits of Triticum monococcum, $T$, urartu, and the A genome of bread wheat (T. aestivum). Theor. appl. Genet., 74, 71-76. 